\title{
Investigation of Servomotor Structure for Sensorless Control Based on High-Frequency Injection Method Masanobu Kakihara ${ }^{* a)}$ Member, Motomichi Ohto** Senior Member, Shinya Morimoto* \\ Member, Senior Member,
}

(Manuscript received Jan. 00, 20XX, revised May 00, 20XX)

\begin{abstract}
This paper presents the servomotor structure suitable for sensorless drives based on high-frequency injection method. The position estimation accuracy is related to the saliency ratio of the motor. Although the motor with increasing saliency ratio with the load has been reported, the mechanism of the phenomenon has not been explained.

In this paper, the improvement in the saliency ratio in a conventional servomotor structure is explained with respect to the magnetic flux distribution. Moreover, the increase in the saliency ratio through further structural improvement is examined, and the effect is confirmed by experiments.
\end{abstract}

Keywords : sensorless drive, high-frequency injection, saliency ratio, servomotor

\section{Introduction}

The sensorless drive technologies are classified into two methods to detect rotor position, one is the back electromotive force (EMF) detection method $^{(2)(3)}$ and the other is high-frequency injection $\operatorname{method}^{(4)-(7)}$. The back EMF detection method has high performance in medium and high-speed regions. But in the low speed range or zero speed the back EMF diminishes and the performance degrades. The high-frequency injection method has the advantages that it is possible to obtain sufficient torque even at low and zero speed. In addition, the position estimation method based on an extended electromotive force (EEMF) combined with signal injection method is proposed which can estimate the position in all speed regions ${ }^{(7)}$. In reference (9), a control method using speed observer and open phase voltages is proposed. This method can detect zero speed without high-frequency injection, but requires a circuit for open phase voltage detection. Therefore, in the industrial field, the high-frequency injection method has been adopted and has already been applied to various applications. The technology is applied not only to the rotary motor but also to the linear motor ${ }^{(10)}$.

However, the injection signal causes an increase in loss and acoustic noise. In reference (11), suppression of acoustic noise caused by voltage injection is discussed. The amplitude and frequency of the injection signal for the required position estimation accuracy depends on the saliency ratio of the motor. Therefore, the characteristics of the motor are an important factor for highfrequency injection methods.

This paper is based on Reference (1), which published in the 23rd International Conference on Electrical Machines and Systems (ICEMS) (2020) (C2020 IEEJ.

a) Correspondence to: Masanobu Kakihara. E-mail: Masanobu.Kakihara@yaskawa.co.jp

* Corporate Technology Division, Yaskawa Electric Corporation, 2-1 Kurosakishiroishi, Yahatanishi-ku Kitakyushu 806-0004, Japan.

** Drives Division, Yaskawa Electric Corporation, 2-1

Kurosakishiroishi, Yahatanishi-ku Kitakyushu 806-0004, Japan.
The saliency ratio of the motor used in a high-frequency injection method depends on the motor structure. It is known that the saliency ratio becomes lower and its phase changes during load conditions. Small size and high torque density motors have a large influence on magnetic saturation, therefore, the above problems become significant. Furthermore, in the servomotor, positioning accuracy is required even under the sensorless control drive. For such problems, studies have been made on control methods and the motor structures.

The control methods considering the cross-coupling of inductances and the design of the motor are examined ${ }^{(12)-(14)}$. And the method of compensating the position estimated by using the cross-coupling components estimated from the injected high frequency signal is proposed ${ }^{(15)}$. In reference (16), a sensorless control based on the high-frequency injection is applied to a servomotor, and improvement of positioning accuracy using the correction by a look-up table is reported.

From the viewpoint of motor structures, the motor design to suppress the phase change due to the cross-coupling of inductances and the reduction in the saliency ratio due to the magnetic saturation has been studied ${ }^{(17)(18)}$. The servomotor in the reference (16) is based on a concentrated-winding IPM structure. Generally, the saliency ratio of the concentrated winding motor is small. In addition, magnetic saturation occurs with the load in the high torque density motor such as a servomotor. Therefore, a reduction of positioning accuracy and maximum torque occurs.

However, the motor shown in reference (16) has features that the saliency ratio increased with the load, and it is considered that a certain degree of magnetic saturation in this motor structure is preferable to keep saliency ratio high at load conditions. These features are not found in other motors, and the details of the phenomenon have not been explained.

In this paper, the phenomenon of increasing the saliency ratio with load is investigated by examining the magnetic flux distribution. Moreover, a motor structure is proposed for further improvement in the saliency ratio, thereby position estimation accuracy. 


\section{Conventional Motor Structure}

2.1 Resolution of position detection In the high frequency injection method, the minimum detection width of the position is expressed as follows ${ }^{(16)}$.

$$
\Delta \theta \propto \frac{\omega_{\text {inj } j \cdot L_{d_{h}} \cdot L_{q_{h}}}}{V_{\text {inj } j}\left|L_{d_{h}}-L_{q_{h}}\right|}
$$

where

$\Delta \theta$ : the minimum detection width of the position

$L_{d_{h}}:$ d-axis high-frequency inductance

$L_{q_{h}}:$ q-axis high-frequency inductance

$V_{i n j}:$ amplitude of high-frequency injection voltage

$\omega_{i n j}$ : frequency of injection voltage

From the equation (1), it is possible to reduce the minimum detection width of the position by increasing the saliency ratio.

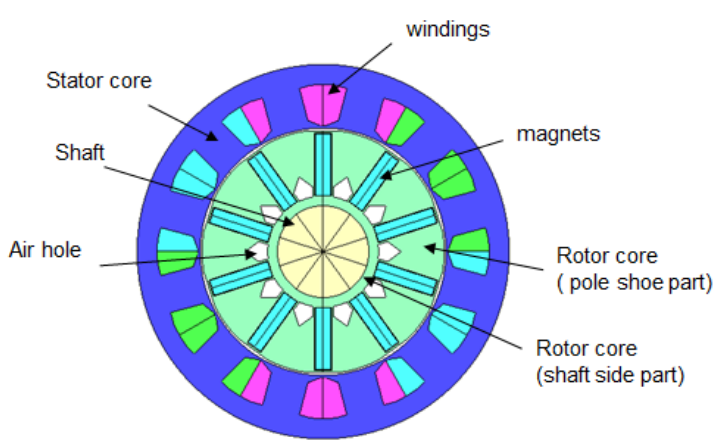

Fig. 1. Structure of conventional motor.

Table 1. Specifications

\begin{tabular}{|c|c|}
\hline Rated Power & $400 \mathrm{~W}$ \\
\hline Rated Speed & $3000 \mathrm{~min}^{-1}$ \\
\hline Rated Current & $2.5 \mathrm{Arms}$ \\
\hline Stator Resistance & $1.36 \Omega$ \\
\hline Nominal Inductance & $2.99 \mathrm{mH}$ \\
\hline Pole Number & 10 \\
\hline
\end{tabular}

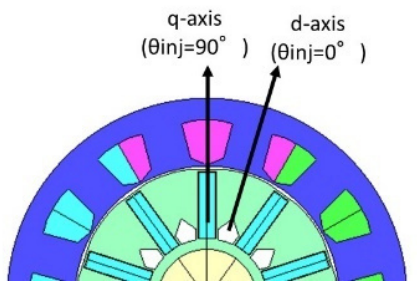

Fig. 2. d,q-axis.

\subsection{Characteristics of High-frequency inductance}

Fig. 1 shows the motor structure used in reference (16). The structure of Fig. 1 is referred to as the conventional structure in this paper. It has a concentrated winding and Interior Permanent Magnet (IPM) structure of 10 poles 12 slots. The magnets are placed radially of the rotor, and the magnetic flux is concentrated to the pole shoe. The rotor core has air holes. Thin bridges of the rotor core exist between air holes and the magnets. The shaft side rotor core is connected by these bridge parts with pole shoe parts. The dimensions of the shape of the hole and bridge parts are decided considering magnetic saturation and a structural aspect.

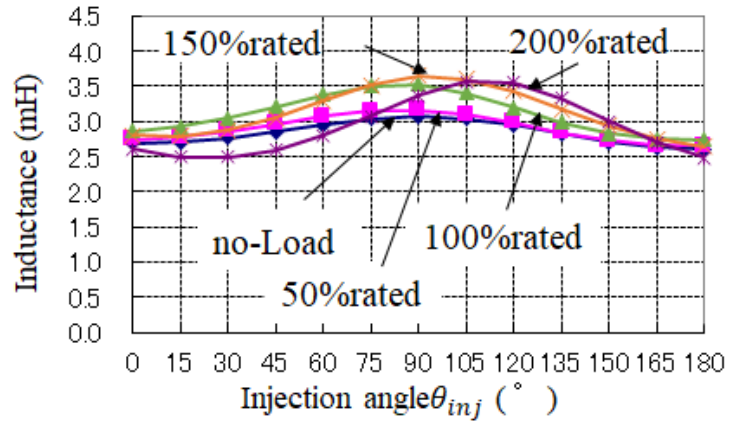

Fig. 3. Relationship between injection angle and inductance. (Analysis)

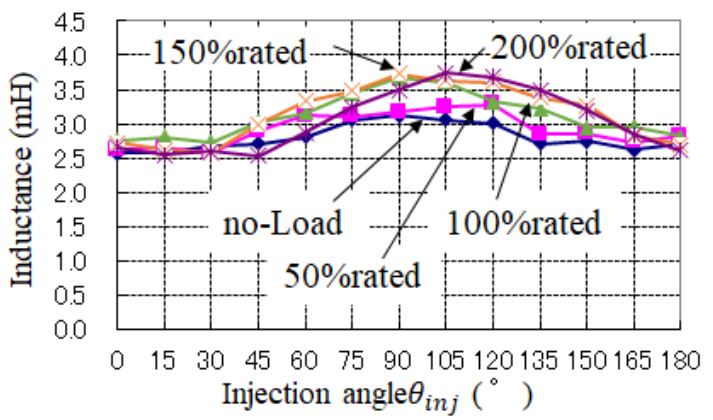

Fig. 4. Relationship between injection angle and inductance. (Measurement)

Table 1 shows the specifications of the motor. Fig. 2 shows the $d$ and $\mathrm{q}$ axis. Inductances are calculated using FEM under applying a high-frequency injection voltage to the winding. The 3-phase voltages of injection component expressed as

$$
\left[\begin{array}{l}
V_{u_{i n j}} \\
V_{v_{i n j}} \\
V_{w_{i n j}}
\end{array}\right]=\left[\begin{array}{cc}
\cos \theta_{i n j} & -\sin \theta_{i n j} \\
\cos \left(\theta_{i n j}-\frac{2}{3} \pi\right) & -\sin \left(\theta_{i n j}-\frac{2}{3} \pi\right) \\
\cos \left(\theta_{i n j}+\frac{2}{3} \pi\right) & -\sin \left(\theta_{i n j}+\frac{2}{3} \pi\right)
\end{array}\right]\left[\begin{array}{c}
V_{h} \\
0
\end{array}\right]
$$

Where

$$
\begin{aligned}
& V_{h}=V_{i n j} \sin \left(\omega_{i n j} t\right) \\
& V_{u_{i n j}}, V_{v_{i n j}}, V_{w_{i n j}}: \text { injection voltage of } \mathrm{U}, \mathrm{V}, \mathrm{W} \text { phase } \\
& \theta_{i n j}: \text { injection angle }
\end{aligned}
$$

The rotor and stator positions are set and fixed as shown in Fig. 2. The frequency of the injection voltage is set to $1 \mathrm{kHz}$ and the amplitude is set to $30 \mathrm{~V}_{\text {rms }}$.

The $\mathrm{d}$-axis and q-axis currents of injection component are expressed as

$$
\left[\begin{array}{l}
I_{d_{h}} \\
I_{q_{h}}
\end{array}\right]=\frac{2}{3}\left[\begin{array}{ccc}
\cos \theta_{i n j} & \cos \left(\theta_{i n j}-\frac{2}{3} \pi\right) & \cos \left(\theta_{i n j}+\frac{2}{3} \pi\right) \\
-\sin \theta_{i n j} & -\sin \left(\theta_{i n j}-\frac{2}{3} \pi\right) & -\sin \left(\theta_{i n j}+\frac{2}{3} \pi\right)
\end{array}\right]\left[\begin{array}{l}
I_{u_{h}} \\
I_{v_{h}} \\
I_{w_{h}}
\end{array}\right]
$$

Where

$I_{u_{h}}, I_{v_{h}}, I_{w_{h}}$ : high-frequency currents of $\mathrm{U}, \mathrm{V}, \mathrm{W}$ phase

$I_{d_{h}}, I_{q_{h}}:$ high-frequency currents of d, q phase

High frequency inductance $L_{h}$ is expressed as follows;

$$
L_{h}=\frac{V_{i n j}}{\omega_{i n j} I_{d_{h}}}
$$




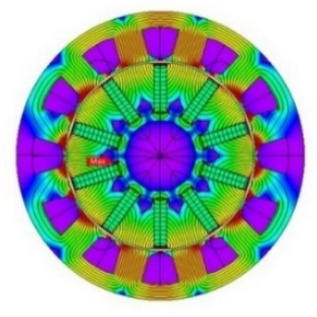

(a) No-Load

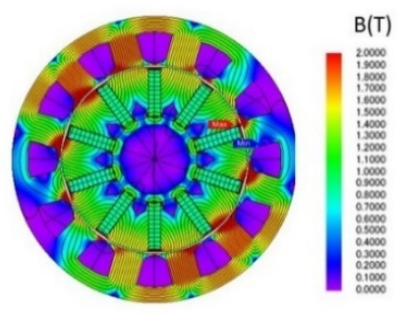

(b) $200 \%$ Load
Fig. 5. Distribution of Magnetic flux and Contour of Magnetic flux density.

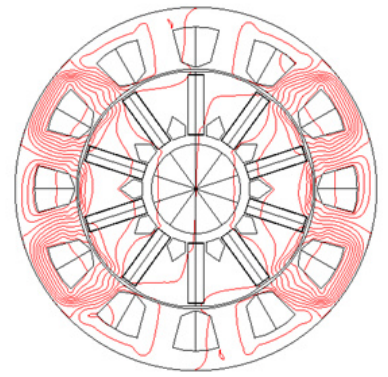

(a) No-load

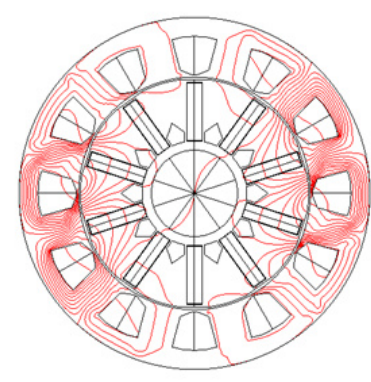

(b) $200 \%$ Load
Fig. 6. Magnetic flux distribution of high-frequency component. $\left(\theta_{\text {inj }}=90^{\circ}\right)$

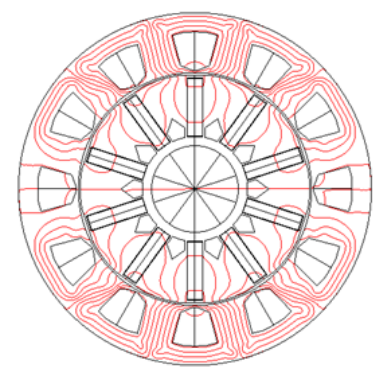

(a) No-load

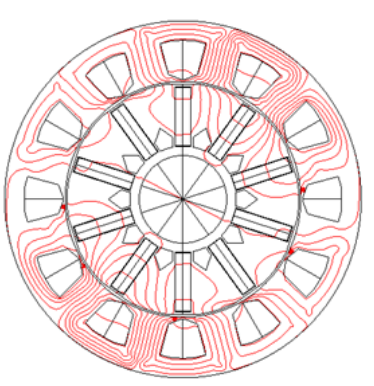

(b) $200 \%$ Load
Fig. 7. Magnetic flux distribution of high-frequency component. $\left(\theta_{i n j}=0^{\circ}\right)$

Fig. 3 and Fig. 4 show the analysis and measurement results of the high-frequency inductances respectively. Both results show a good agreement. The high-frequency inductance of the maximum value is increased with the load current increase. The reason why the saliency ratio increases with the load can be explained based on magnetic flux distribution.

Fig. 5 (a) and (b) shows the distribution of the main magnetic flux and the contour of magnetic flux density at no load and $200 \%$ load respectively. The tip part of the stator teeth has a high magnetic flux density even at no load. Although the magnetic flux density of the motor is high at load, the magnetic flux density of a part of the motor such as the stator teeth tip becomes low, and the saturation level mitigates.

Fig. 6 and Fig. 7 show distributions of high-frequency flux components when the injection angles are $\theta_{i n j}=90^{\circ}$ and $0^{\circ}$ respectively. To confirm the flow of the magnetic flux caused only by the high-frequency current, load field components produced by excitation sources need to be separated. So, a high-frequency current $I_{h}=1 \mathrm{~A}$ is applied, and the high-frequency flux distribution is calculated as the difference before and after injecting the highfrequency current $I_{h}$.

Fig. 6 is a case that the injection angle of the high-frequency current is set to $90^{\circ}$ which corresponds to the state of $90^{\circ}$ in Fig. 2 . Fig. 6 (a) and (b) are cases when a high-frequency current is applied at no load and $200 \%$ load respectively. In Fig.6 (a), the highfrequency magnetic flux passes through the rotor pole shoe surface. This shows the distribution of magnetic flux of the so-called q-axis component. In Fig. 6 (b), the high-frequency magnetic flux at load passes through the stator teeth tip part that magnetic saturation is relaxed. Therefore, the amount of high-frequency magnetic flux component is increased. The phenomenon that the q-axis highfrequency magnetic flux becomes higher at load is considered to be due to saturation relaxation of the magnetic flux density by the main magnetic flux. Although details are not mentioned in this paper, magnetic flux passes not only to the rotor pole shoe surface but also to the next pole at load. The magnetic flux is related to the so-called cross-coupling and phase shift.

Fig. 7 is a case of the injection angle of the high-frequency current is set to $0^{\circ}$, which corresponds to $0^{\circ}$ in Fig. 2. Highfrequency magnetic flux corresponds to the d-axis magnetic flux. Changes in the magnetic flux distribution at load are small compared with the one at no-load. So, it is not affected much load current. The high-frequency magnetic flux flows the same path as the main magnetic flux. Therefore, by adjusting the magnetic flux density of the main magnetic flux in the stator teeth part, it is considered possible to suppress the amount of the high-frequency magnetic flux and reduce the $L_{h}$ at $0^{\circ}$.

\section{Proposed Motor Structure}

Fig. 8 shows the proposed structure. The grooves are provided in the stator teeth. It can be expected that the d-axis component of the high-frequency magnetic flux is suppressed by provided grooves.

Fig. 9 shows the analysis results of the high-frequency inductance and Fig. 10 shows the measurement results. Both results show a good agreement. In the case of the proposed structure, the maximum value of the high-frequency inductance is also increased with the load current increase. The maximum value of inductances shows the same value as the conventional structure. The inductance at around $\theta_{i n j}=0^{\circ}$ is reduced in the analysis. It is the effect of the groove. In the measurements, the difference from the conventional structure is small, but the value has also decreased by the provided groove.

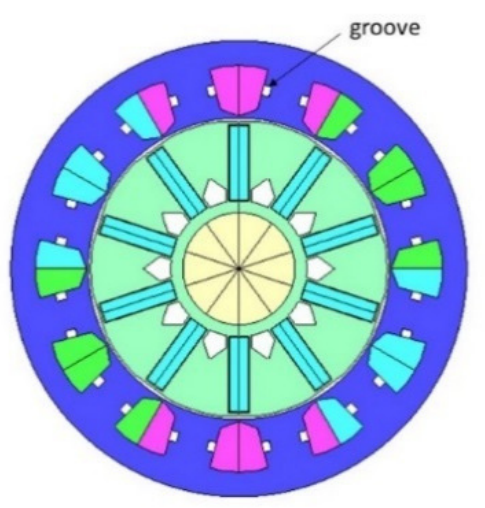

Fig. 8. Structure of proposed motor. 


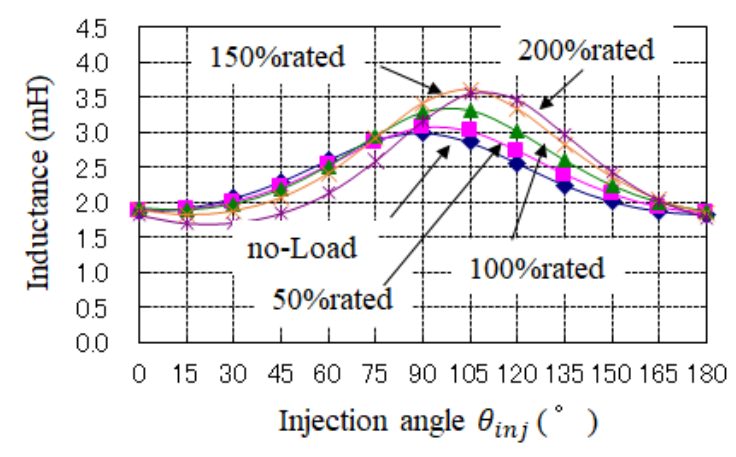

Fig. 9. Relationship between injection angle and inductance. (Analysis)

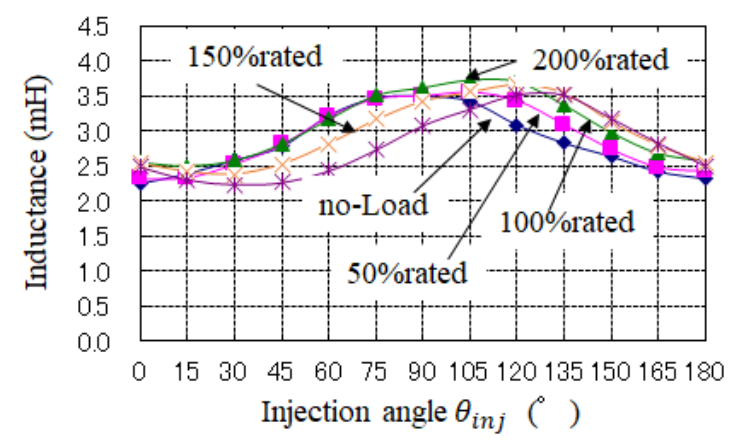

Fig. 10. Relationship between injection angle and inductance. (Measurement)

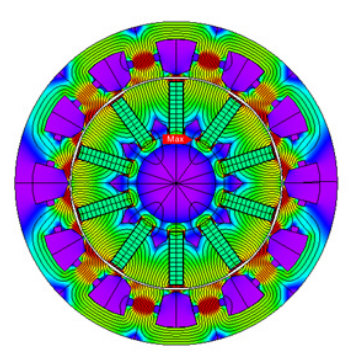

(a) No-load

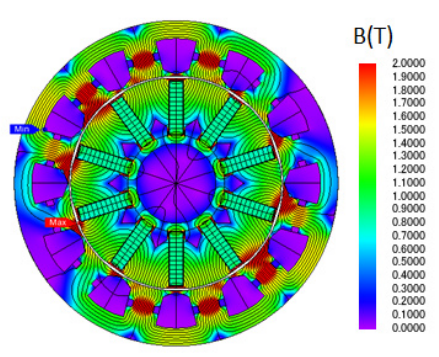

(b) $200 \%$ load
Fig. 11. Distribution of magnetic flux and contour of magnetic flux density.

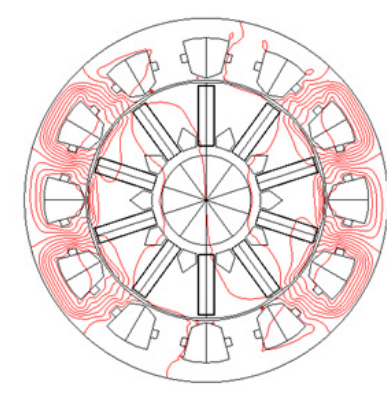

(a) No-load

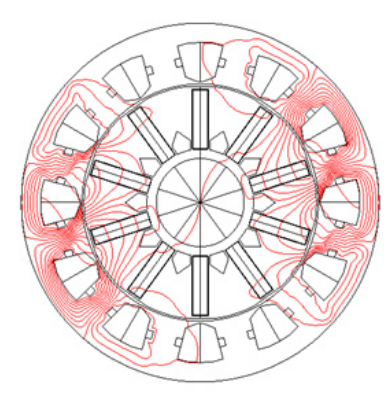

(b) $200 \%$ load
Fig. 12. High-frequency component of magnetic flux.

$$
\left(\theta_{i n j}=90^{\circ}\right)
$$

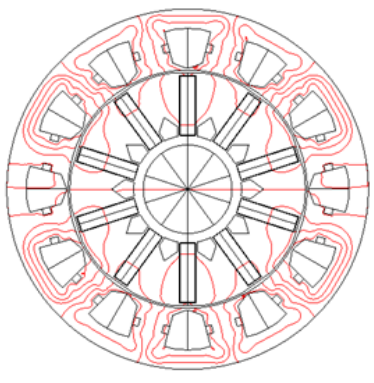

(a) No-load

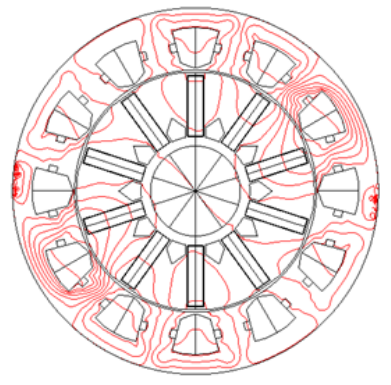

(b) $200 \%$ load
Fig. 13. High-frequency component of magnetic flux. $\left(\theta_{i n j}=0^{\circ}\right)$

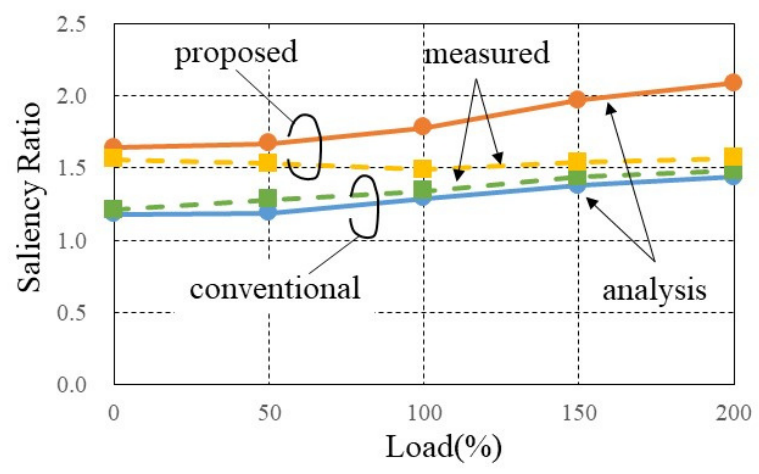

Fig. 14. Characteristic of saliency.

Fig. 11 shows the distribution of the main magnetic flux. The magnetic flux density is locally higher around the groove in the stator teeth part. Fig. 12 and 13 show high-frequency flux distributions. Fig. 12 shows the case of the $\theta_{i n j}=90^{\circ}$ and Fig. 13 is the case of $\theta_{i n j}=0^{\circ}$. The tendency of the flow pattern of the highfrequency magnetic flux is the same as the conventional structure. In the case of $\theta_{i n j}=0^{\circ}$, the amount of magnetic flux is reduced, and the $L_{h}$ is considered to be decreased.

Fig. 14 shows the saliency ratio characteristics according to the load. Here, the saliency ratio is a ratio between the maximum value and the minimum value of the high-frequency inductances shown in Fig. 9 and Fig. 10. The saliency of the proposed structure is increased compared with the conventional structure. In the conventional structure, the measurement and analysis results are in good agreement. In the improved structure, the saliency ratio increases with the load in the analysis, but it remains almost constant in the measurement. The reason that the measured value of $\mathrm{d}$-axis inductance is larger than the analysis value, the influence of magnetic saturation is different in the actual machine and the analysis.

Table 2 shows the values of $L_{d h}$ and $L_{q h}$ at no load. $L_{d h}$ is the value at $\theta_{i n j}=0^{\circ}$, and $L_{q h}$ is the value at $\theta_{i n j}=90^{\circ}$ in Fig. 3, 4, 9 and 10. By substituting these inductance values into the equation (1), the minimum detection width of the position can be calculated. The proposed structure's one is approximately $25 \%$ smaller in the analysis and approximately $40 \%$ smaller in the measurement than the conventional structure. Significant improvements can be expected. Table 3 shows the value of $L_{d h}$ and $L_{q h}$ at $200 \%$ load. These values are not minimum and maximum values. The positions of maximum and minimum deviate form $\theta_{i n j}=0^{\circ}$ and $90^{\circ}$ owing to the cross-coupling phenomenon. However, the saliency ratio almost 
Table 2. Inductance parameter (at no-load)

\begin{tabular}{|c|c|c|c|c|}
\hline \multirow{2}{*}{} & \multicolumn{2}{|c|}{ Analysis(mH) } & \multicolumn{2}{c|}{ Measure $(\mathrm{mH})$} \\
\cline { 2 - 5 } & $L_{d h}$ & $L_{q h}$ & $L_{d h}$ & $L_{q h}$ \\
\hline$\theta_{i n j}$ & 0 & 90 & 0 & 90 \\
\hline conventional & 2.7 & 3.1 & 2.6 & 3.1 \\
\hline proposed & 1.9 & 3.0 & 2.3 & 3.5 \\
\hline
\end{tabular}

Table 3. Inductance parameter (at 200\%Load)

\begin{tabular}{|c|c|c|c|c|}
\hline \multirow{2}{*}{} & \multicolumn{2}{|c|}{ Analysis(mH) } & \multicolumn{2}{c|}{ Measure $(\mathrm{mH})$} \\
\cline { 2 - 5 } & $L_{d h}$ & $L_{q h}$ & $L_{d h}$ & $L_{q h}$ \\
\hline$\theta_{i n j}$ & 0 & 90 & 0 & 90 \\
\hline conventional & 2.6 & 3.4 & 2.7 & 3.5 \\
\hline proposed & 1.8 & 3.2 & 2.5 & 3.1 \\
\hline
\end{tabular}

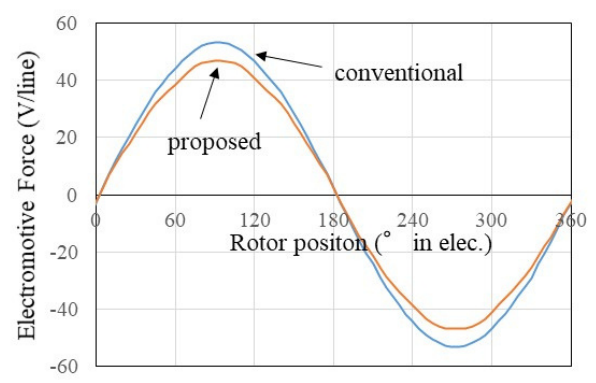

Fig.15. EMF wave form.

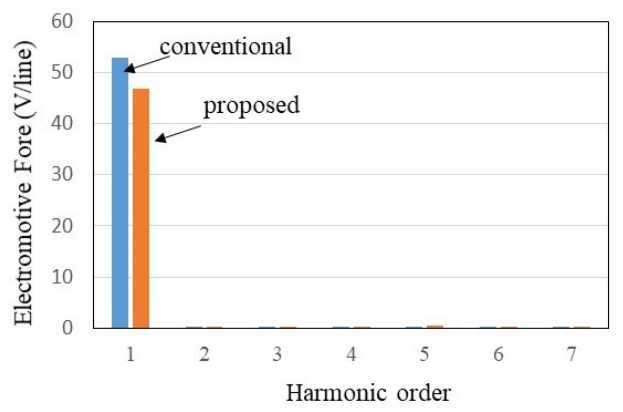

Fig. 16. Harmonic components of EMF waveform.

same value compared the one at no-load.

Fig. 15 and Fig. 16 shows the electromotive force (EMF) waveform and harmonic components respectively. The EMF of the proposed motor decreased by $10 \%$ compared with the conventional one. So, in order to obtain the same output power, it is necessary to increase the current by $10 \%$. The size of grooves affects the magnetic saturation of stator teeth, which determines the reduction of d-axis inductance and EMF. Since the relation between saliency ratio and EMF is a trade-off relation. The size of grooves' length and depth are decided using FEM analysis so that saliency ratio becomes large as much as possible within the allowable range of EMF decrease. However EMF of the proposed motor decreases, sensorless drive performance can be greatly improved.

Fig. 17 shows a change due to the position of the line-inductance. In the control method of the d-axis search type, the minimum portion of the inductance is recognized as the d-axis at the initial position estimation.

If the minimum portion of the inductance is flat, the estimated position error of the d-axis increases. In the proposed structure, it

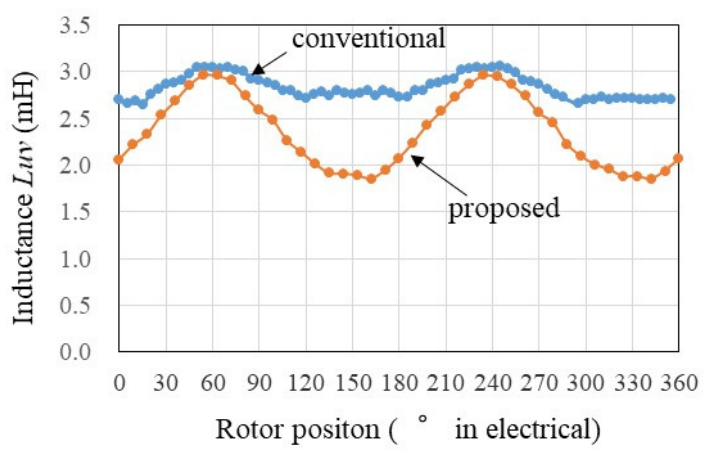

(a) Analysis

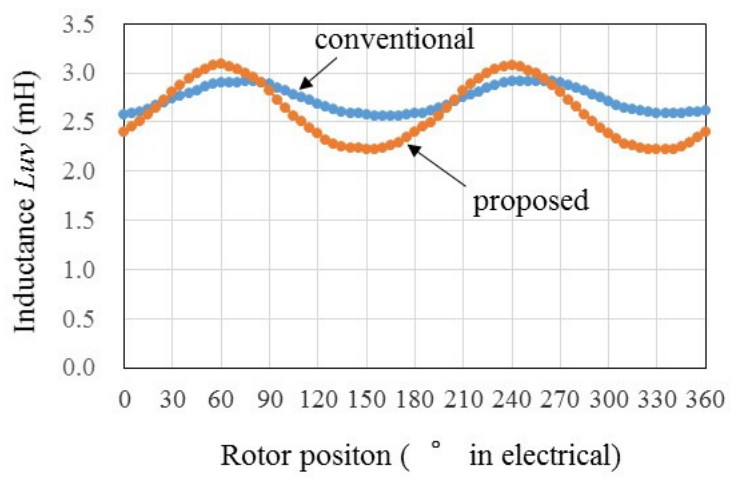

(b) Measurement

Fig. 17. Relationship between rotor position and inductance.

becomes more to sinusoidal, and improvement of the initial position estimation can be expected. The difference between the maximum value and the minimum value is also increased, the saliency ratio is increased.

Fig. 17 (b) shows the measured value. Although the distortion is smaller than the analysis in the conventional structure, it can be seen that the saliency ratio is increased in the proposed structure.

\section{Experiment}

4.1 Control method Fig. 18 shows a control block diagram. The position estimation method using a square wave voltage synchronized with $\mathrm{PWM}^{(16)(19)}$ is applied. The method is described below.

The voltage equation in the synchronous reference frame (rotor $\mathrm{d}-\mathrm{q}$ coordinate system) is expressed as

$\left[\begin{array}{l}v_{d} \\ v_{q}\end{array}\right]=\left[\begin{array}{cc}R+L_{d} p & -\omega L_{q} \\ \omega L_{d} & R+L_{q} p\end{array}\right]\left[\begin{array}{c}i_{d} \\ i_{q}\end{array}\right]+\left[\begin{array}{c}0 \\ \omega \phi\end{array}\right]$

where $v_{d}$ and $v_{q}$ are d-axis and q-axis voltages, respectively, $R$ is electric resistance of one phase, $L_{d}$ and $L_{q}$ are d-axis and q-axis inductances, respectively, $\phi$ is d-axis linkage magnetic flux, $p=$ $\mathrm{d} / \mathrm{dt}$ is a differential operator of time, and $\omega$ is rotation angular speed in electrical radian per seconds.

If the frequencies of injected voltage and current are much higher than the synchronous frequency of the motor, product terms of inductance and differentiated current are much more significant than other terms in equation (5). Thus, equation (5) can be 


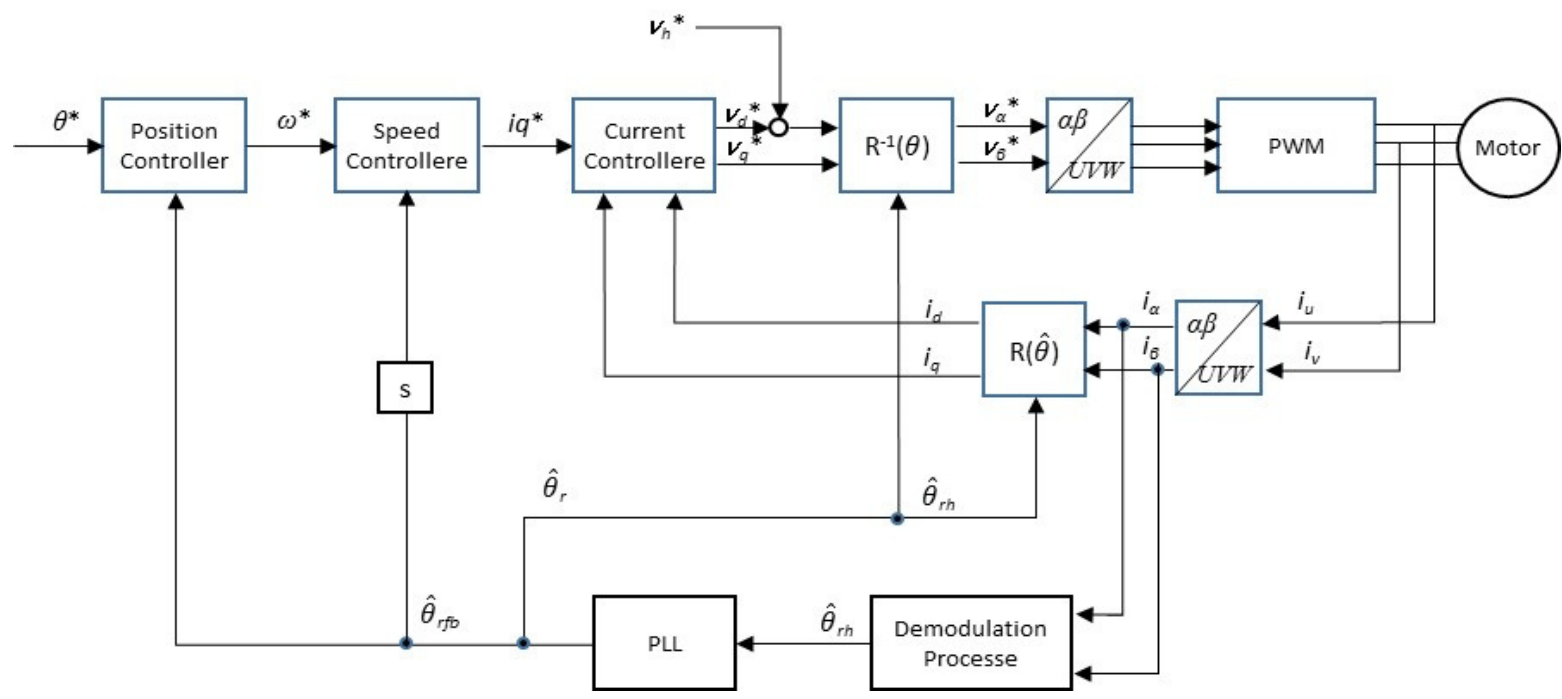

Fig. 18. Control block diagram

approximated as

$\left[\begin{array}{c}v_{d h} \\ v_{q h}\end{array}\right]=\left[\begin{array}{cc}L_{d h} p & 0 \\ 0 & L_{q h} p\end{array}\right]\left[\begin{array}{l}i_{d h} \\ i_{q h}\end{array}\right]=\left[Z_{d q}\right]\left[\begin{array}{l}i_{d h} \\ i_{q h}\end{array}\right]$

where subscript " $h$ " means that the value is concerned with highfrequency signal.

When a pulsating voltage is injected into the d-axis of the estimated rotor reference frame, injected high-frequency voltage can be described as in equation (7).

$$
\left[\begin{array}{l}
v_{d h} \\
v_{q h}
\end{array}\right]=\left[\begin{array}{c}
V_{i n j} \cos \omega_{h} t \\
0
\end{array}\right]
$$

where $V_{i n j}$ is the magnitude and $\omega_{h}$ is the angular frequency of injection voltage.

Transforming equation (6) to the stationary reference frame as shown in equation (8).

$$
\begin{aligned}
& {\left[\begin{array}{l}
i_{\alpha h} \\
i_{\beta h}
\end{array}\right]=\left[\mathbf{R}\left(\theta_{r}\right)\right]^{-1}\left[Z_{d q}\right]^{-1}\left[\mathbf{R}\left(\theta_{r}\right)\right]\left[\begin{array}{l}
v_{\alpha h} \\
v_{\beta h}
\end{array}\right]} \\
& =\left[\mathbf{R}\left(\theta_{r}\right)\right]^{-1}\left[Z_{d q}\right]^{-1}\left[\begin{array}{l}
v_{d h} \\
v_{q h}
\end{array}\right]
\end{aligned}
$$

where $\theta_{r}$ is the rotor position, $\mathbf{R}$ is the rotation matrix.

Assuming that the estimation error of the rotor position is small enough, then equation (8) is simplified to equation (9).

$$
\begin{aligned}
& {\left[\begin{array}{l}
i_{\alpha h} \\
i_{\beta h}
\end{array}\right]=\left[\mathbf{R}\left(\theta_{r}\right)\right]^{-1}\left[Z_{d q}\right]^{-1}\left[\begin{array}{c}
V_{i n j} \cos \omega_{h} t \\
0
\end{array}\right]} \\
& =\frac{V_{i n j} \sin \omega_{h} t}{L_{d h} \omega_{h}}\left[\begin{array}{l}
\cos \theta_{r} \\
\sin \theta_{r}
\end{array}\right]
\end{aligned}
$$

Therefore, the rotor position $\hat{\theta}_{r h}$ can be estimated by the arctangent operation as follows.

$$
\hat{\theta}_{r h}=\tan ^{-1}\left(\frac{\frac{i_{\beta h}}{\sin \omega_{h} t}}{\frac{i_{\alpha h}}{\sin \omega_{h} t}}\right)
$$

The currents $i_{\alpha h}$ and $i_{\beta h}$ are obtained from the detected current through a Band Pass Filter of the superimposed frequency components. Further, the Low Pass Filter is required to remove the noise component at the position detected by equation (10). However, since the servo system requires responsiveness, it is necessary to reduce the delay in position calculation. Therefore a method to inject square wave voltage in d-axis of the estimated rotor reference frame is proposed ${ }^{(16)}$. The injected voltage can be described as following equation (11).

$$
\mathrm{V}_{h}[n]=\left\{\begin{aligned}
V_{i n j}, & n=2 m \\
-V_{i n j}, & n=2 m+1(m=0,1,2, \cdots)
\end{aligned}\right.
$$

Fig. 19 shows the square wave voltage and its response current. The current response to the square wave voltage changes like a triangular wave by referring to the switching point of the square

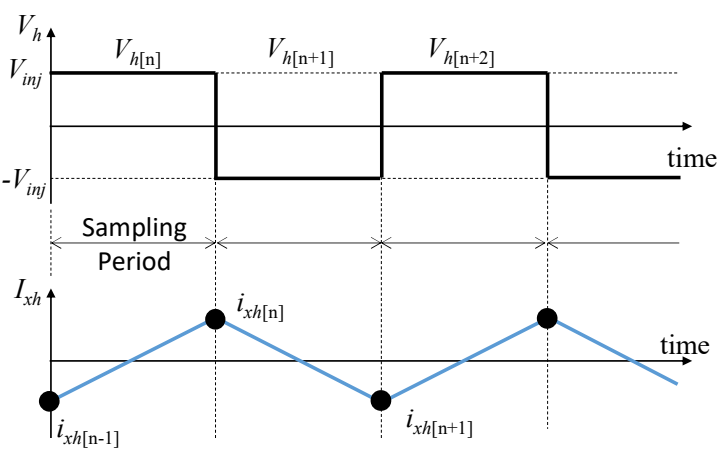

Fig. 19. Waveforms of the PWM voltage and injected voltage and the response current. 


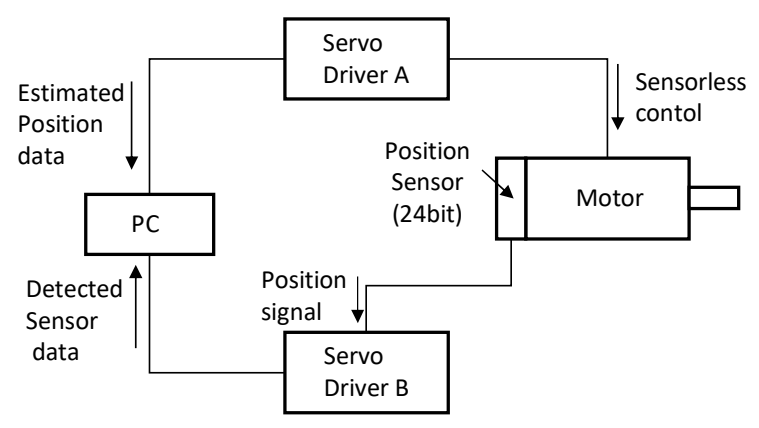

Fig. 20. Experimental system configuration

Table 4. Specification of Servo Driver A

\begin{tabular}{|c|c|c|}
\hline Output Power & $\mathrm{W}$ & 400 \\
\hline Rated Voltage & $\mathrm{Vrms}$ & 200 \\
\hline Rated Current & $\mathrm{Arms}$ & 2.9 \\
\hline Carrier Frequency & $\mathrm{kHz}$ & 10 \\
\hline Injection signal frequency & $\mathrm{kHz}$ & 10 \\
\hline Injection signal voltage & $\mathrm{Vrms}$ & 100 \\
\hline Position control gain & $1 / \mathrm{s}$ & 40 \\
\hline
\end{tabular}

wave that is the sampling point. As shown in equation (12), the envelope $\left(I_{\cos }[n], I_{\sin }[n]\right)$ of high frequency current components can be extracted by multiplying the difference of the current for each sampling by the sign of the injection voltage.

$$
\left[\begin{array}{l}
I_{\cos }[n] \\
I_{\sin }[n]
\end{array}\right]=\operatorname{sign}\left(V_{h}[n]\right)\left[\begin{array}{l}
i_{\alpha h}[n]-i_{\alpha h}[n-1] \\
i_{\beta h}[n]-i_{\beta h}[n-1]
\end{array}\right]
$$

From the envelope obtained by (12), the position $\hat{\theta}_{r h}[n]$ can be estimated as in equation (13).

$$
\hat{\theta}_{r h}=\tan ^{-1}\left(\frac{I_{\sin }[n]}{I_{\cos }[n]}\right)
$$

The envelope operation of equation (12) is more robust to noise compared to equation (9), so no filter is necessary. Therefore, the delay in position estimation can be reduced.

However, this method estimates the minimum portion of inductance as d-axis, so the positioning error increases depending on the load. In order to reduce the position estimation error at load, the position compensation method using the approximation function of the position estimation error by the torque command ${ }^{(16)}$ is adopted. Alternatively, similar results can be achieved by applying a position compensation method based on the crosscoupling factor ${ }^{(13)(15)}$.

4.2 Experimental system and measurement method Fig. 20 shows the experimental system. Servo Driver A controls the rotor position of the motor by sensorless control. However, the position compensation is not used because the effect of improving the saliency ratio is evaluated in this experiment. The measurement PC gives a position command to Servo Driver A and collects the estimated position from Servo Driver A.

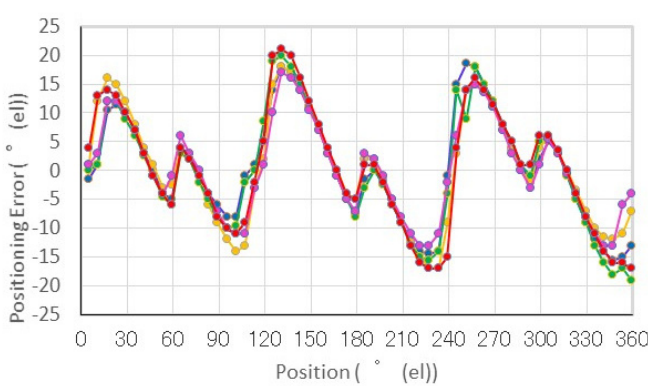

(a) Conventional structure

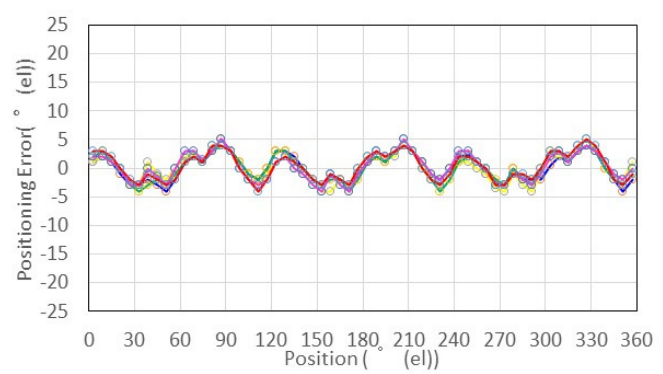

(b) Proposed structure

Fig. 21. Positioning error

Table 5. Experimental results of positioning error.

\begin{tabular}{|c|c|c|}
\hline Motor structure & conventional & proposed \\
\hline Positioning error & $\pm 20^{\circ}$ & $\pm 5^{\circ}$ \\
\hline
\end{tabular}

The motor is equipped with a 24 bits position sensor. Servo Driver B detects the rotor position from the signal of the position sensor, and the detected rotor position data is collected by the measurement PC. The measurement PC calculates the difference between the estimated rotor position and the detected rotor position after positioning the rotor as a positioning error. Here, positioning means that the estimated feedback position by sensorless control coincides the position command.

Table 4 shows the specification of Servo Driver A including high frequency injection condition. The injection signal is $1 \mathrm{kHz}$ and $30 \mathrm{~V}$ in the simulation, but is set to $10 \mathrm{kHz}$ and $100 \mathrm{~V}$ in the experiment. This is to obtain sufficient position detection performance even with a conventional motor having a low saliency ratio.

4.3 Measured result $\quad$ Fig. 21 shows the positioning error. The motor has 10 poles, and one mechanical angle period is equivalent to five electrical angle periods. In Fig. 21, the positioning error is shown for one electric period.

Table 5 shows the experimental results of the positioning error. The positioning error of the conventional structure has a maximum of $\pm 20^{\circ}$, whereas the proposed structure has maximum of about $\pm 5^{\circ}$, and it is approximately $25 \%$ of the conventional structure. This reduction in position error is due to the saliency ratio improvement described in the previous section.

\section{Conclusion}

The motor structure was investigated to improve sensorless drive performance. The phenomenon that the saliency ratio increases with the load in the conventional structure was clarified based on the magnetic flux distribution of the high frequency that it due to 
local relaxation of magnetic saturation by the load current.

This paper also proposed a structure with a groove on a part of the stator teeth. In the proposed structure, it was shown that the saliency ratio is increased, and it is possible to further reduce the positioning error.

\section{References}

(1) Masanobu Kakihara, Mamoru Takaki, Motomichi Ohto, Shinya Morimoto, "An Investigation of Servo Motor Structure for Sensorless Control Based on High-Frequency Injection Method", The 23rd International Conference on Electrical Machines and Systems (ICEMS), LS5B-3 (2020)

(2) S. Morimoto, K. Kawamoto, M. Sanada and Y. Takeda, "Sensorless control strategy for salient-pole PMSM based on external EMF in rotating reference frame", IEEE Trans. Ind. Appl., vol. 38, No.4, pp.1054-1061 (2002)

(3) S. C. Yang and R. D. Lorenz, "Surface Permanent-Magnet Machine SelfSensing at Zero and Low Speeds Using Improved Observer for Position, Velocity, and Disturbance Torque Estimation”, IEEE Trans.Ind.Appl., vol. 48, No. 1, pp. 151-160 (2012)

(4) J. H. Jang, J. I. Ha, M. Ohto, K. Ide, and S. K. Sul, "Analysis of permanent Magnet machine for sensorless control based on high-frequency signal injection”, IEEE Trans. Ind. Appl., vol. 40, no. 6, pp. 1595-1604 (2004)

(5) S. K. Sul and S. Kim, "Sensorless control of IPMSM: Past, present, and future," IEEJ J. Ind. Appl., vol. 1, no. 1, pp. 15-23 (2012)

(6) S. K. Sul, Y. C. Kwon, Y. Lee, "Sensorless Control of IPMSM for Last10 Years and Next 5 Years", IEEE CES Trans. Elec. Mach. \& Sys.,vol. 1, NO. 2, pp. 91-99 (2017)

(7) F. Briz, M W. Degner "Rotor position estimation", IEEE Industrial Electronics Magazine, vol. 5, Issue. 2, pp. 24-36 (2011)

(8) Ryoh Saitoh, Yuki Makaino, Takumi Ohnuma, Adaptive Signal Injection Method Combined with EEMF-based Position Sensorless Control of IPMSM Drives, IEEJ Journal of Industry Applications, Vol.4, No.4, p. 454-459 (2015)

(9) Sari Maekawa, Mengyue Wu, Hisao Kubota, Position Sensorless Control Method for Permanent Magnet Synchronous Motors Using Speed Observer and Opened Phase Voltage Caused by Magnetic Saliency, IEEJ Journal of Industry Applications, Vol8, No.6, p. 875-883 (2019)

(10) Shogo Makino, Masanobu Kakihara, Yoshiyasu Takase, Mamoru Takaki, Toru Shikayama, Motomichi Ohto,Tsuyoshi, Higuchi and Takashi Abe, "Development of inductor linear motor for high-Speed drive" ,IEEE Trans.Ind. Appl., vol 53,Issue 5.,pp. 4559-4568 (2017)

(11) Naoki Kawamura, Tadanao Zanma, Kenta Koiwa, Kang-Zhi Liu, Masaru Hasegawa, "Position Sensorless Adaptive Positioning Servo System with Simplified Differential Calculation and High-Frequency Voltage Injection Strategy Considering Acoustic Noise Suppression", IEEJ Journal of Industry Applications, Vol.10, No.1, p. 1-10 (2021)

(12) Z. Q. Zhu, Y. Li, D. Howe, C. M. Bingham, "Compensation for Rotor Position Estimation Error due to Cross-Coupling Magnetic Saturation in Signal Injection Based Sensorless Control of PM Brushless AC Motors", IEMDC2007, vol.1, pp. 208-213 (2007)

(13) Y. Li, Z. Q. Zhu, D. Howe, C. M. Bingham, D. Stone, "mproved RotorPosition Estimation by Signal Injection in Brushless AC Motors, Accounting for Cross-Coupling Magnetic Saturation", IEEE Trans.Ind. Appl., Vol. 45, Issue 5 (2009)

(14) Y. Kano, T. Kosaka, N. Matsui, and T. Nakanishi, "Design of saliency based sensorless drive IPM motors for general industrial applications", in Proc. IEEE Ind. Appl. Soc. Annu. Meet., pp. 1-6 (2008)

(15) S. Morimoto, K. Shimamoto, M. Kakihara, T. Hanamoto: "Improving Position Estimation Accuracy of Magnetic Saliency Based Sensorless Control by Considering Cross-Coupling Factor", IEEJ Journal IA, Vol.10, No.1, pp.18-26 (2021)

(16) Shinya Morimoto, K.Shimamoto, T. Hanamoto, "Realization of High Torque Density Encoderless Servo Drive System” IECON 2019 - 45th Annual Conference of the IEEE Industrial Electronics Society, pp.1120-1125 (2019)

(17) K. Ide, M. Takaki, S. Morimoto, Y. Kawazoe, A. Maemura, and M. Ohto, "Saliency-based sensorless drive of an adequately designed IPM motor for robot vehicle application," in Proc. Conf. Rec. Power Convers. Conf., pp. 1126-1133 (2007)

(18) S. Murakami, T. Shiota, M. Ohto, K. Ide, and M. Hisatsune, "Encoderless servo drive with adequately designed IPMSM for pulse-voltage injectionbased position detection," IEEE Trans. Ind. Appl., vol. 48, no. 6, pp. 1922$1930(2012)$

(19) Y. D. Yoon, S. K. Sul, S. Morimoto, and K. Ide, "High-Bandwidth Sensorless Algorithm for AC Machines Based on Square-Wave-Type Voltage Injection," IEEE Trans. Ind. Appl., pp. 1361-1370, Vol. 47, No. 3 (2011)

Masanobu Kakihara (Member) He received B.S. and M.S. degrees in

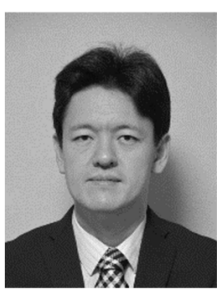
electrical engineering from Kyushu University, Fukuoka, Japan, in 2003 and 2005, respectively. In 2005, he joined Yaskawa Electric Corporation, Kitakyushu, Japan, where he is currently a Member of the Motor Actuator Fundamental R\&D Management Dept., Corporate Technology Division. His current research interests include the design and development of servomotors and actuators.

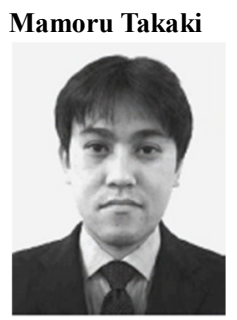

(Member) He received B.S. degree in electrical engineering from Kyushu Institute of Technology, Kitakyushu City, Japan, in 1999. In 1999, he joined Yaskawa Electric Corporation, Kitakyushu, Japan, where he is currently an Assistant Manager of Drives Fundamental R\&D Management Dept., Corporate Technology Division. His current research interests are high performance motor control.

Motomichi Ohto

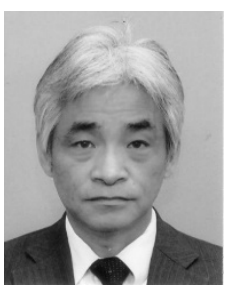

Shinya Morimoto

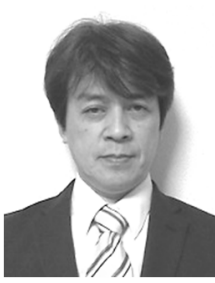

Senior Member) He received the B.Eng., M.Eng., and D.Eng. degrees in electrical engineering from Oita University, Oita, Japan, in 1984, 1986, and 2005, respectively. Since 1986, he has been with Yaskawa Electric Corporation, Kitakyushu, Japan, and he is now with Planning Dept., Drives Division. He has worked on development technologies related to electromagnetic field analysis and electric motors.

(Senior Member) He received the B.S. and Ph.D. degrees from Kyushu Institute of Technology, Kitakyushu City, Japan, in 1990 and 2020, respectively. He is presently a chief manager of Drives Fundamental R\&D Management Dept., Corporate Technology Division. in Yaskawa Electric Corporation. He has worked on development of motor-drive control and power conversion technology. He is a member of SICE Japan, ISCIE Japan and IEEE IAS. 